\title{
The Best at the Top? Candidate Ranking Strategies Under Closed List Proportional Representation
}

\author{
Benoit S Y Crutzen \\ Erasmus School of Economics \\ Nicolas Sahuguet \\ HEC Montreal
}

Hideo Konishi

Boston College

April 21, 2021

\begin{abstract}
Under closed-list proportional representation, a party's electoral list determines the order in which legislative seats are allocated to candidates. When candidates differ in their ability, parties face a trade-off between competence and incentives. Ranking candidates in decreasing order of competence ensures that elected politicians are most competent. Yet, party list create incentives for candidates that may push parties not to rank candidates in decreasing competence order. We examine this trade-off in a gametheoretical model in which parties rank their candidate on a list, candidates choose their campaign effort, and the election is a team contest for multiple prizes. We show that the trade-off between competence and incentives depends on candidates' objective and the electoral environment. In particular, parties rank candidates in decreasing order of competence if candidates value enough post-electoral high offices or media coverage focuses on candidates at the top of the list.
\end{abstract}




\section{Introduction}

Competent politicians are key for government and democracy to function well. In most democracies, political parties select the candidates who can run for office. Parties' decision on which candidates to let run under their banner is therefore of fundamental importance. When they select candidates, parties have to worry not only about the competence of candidates but also about incentives, about their candidates' motivation to engage with voters and work hard for their party's electoral success.

Under closed-list proportional representation $(\mathrm{PR}),{ }^{1}$ the legislative seats a party wins are allocated to its candidates following the order of its electoral list. In this context, the parties' selection decisions become even more complex as they need not only decide which candidates to let run under their banner, but also how to rank them on their electoral list. As shown in Crutzen, Flamand, and Sahuguet (2020), each position on the list generates distinct incentives for candidates.

In this paper, we develop a formal model to analyze the conditions under which parties rank their candidates in decreasing order of competence. This ordering is particularly appealing to voters as it always ensures that the most competent candidates get elected. Yet, parties do not always follow this strategy. For example, parties are found to rank candidates in decreasing order of competence in Dal Bo et al., 2017 and Cox et al., 2020 but not in Galasso and Nannicini, 2015 or Cirone, Cox and Fiva, 2020. In our analysis, we zoom in on five aspects of elections: candidates' individual desire to get elected to parliament, candidate's ideology, how ideologically polarized parties are, the availability of post-electoral executive positions or other high offices (such as that of Speaker of the House), and the influence of the media.

Two parties compete in a nation-wide legislative election. Parties have access to a pool of candidates and wish to maximize their share of legislative seats. ${ }^{2}$ Before the election, candidates are assigned to a position on the list. Knowing their position, they exert costly

\footnotetext{
${ }^{1}$ Proportional representation is the electoral system used in a majority of modern democracies (Cruz, Keefer and Scartascini, 2018).

${ }^{2}$ We assume that the size of the pool corresponds to the number of available seats in parliament. Before deciding on how to rank candidates on the list, parties wish to select the most competent candidates available. Setting the number of candidates to be equal to the number of legislative seats is thus without loss of generality.
} 
campaigning effort. Effort represents the time and energy spent by candidates in all activities they undertake to improve their party's electoral success. Effort should thus be interpreted broadly as any costly action to mobilize voters who are on the fence about going to the voting booth or to persuade undecided citizens to vote for a specific party. Such campaigning efforts may very well be welfare decreasing for the population at large, but they are instrumental to parties' electoral strategy and goals. Candidates may differ in their marginal cost of effort, which we interpret as their competence. Highly competent candidates are more effective during the campaign (and in any post-electoral position). When setting up their electoral lists, parties take into account the incentive effects of their lists on candidates.

The incentive effects of party lists are driven by four different forces. First, candidates are opportunistic, motivated by the desire to be elected to the legislature. Second, at least for politicians at the top of their party list, the prospect of obtaining a high office post-election generates further incentives. Third, candidates are driven by ideology, they are motivated by their party winning control of the executive and thus implementing its electoral program. This ideological motivation is proportional to the degree of ideological polarization between parties. Finally, the media influences candidates' decisions as media coverage determines the visibility of candidates' efforts and their influence on their party's electoral success.

The efforts of all candidates on a party list determine that party's electoral output. This output determines how appealing a party is to voters. The probability that a party wins $a$ given seat is then determined in a Tullock contest based on the parties' electoral outputs. A party's probability of winning a certain number of seats then follows a binomial distribution with, as key parameters, the total number of seats in the legislature and the Tullock probability based on parties' outputs.

When candidates only care about winning a legislative seat and all candidates are equally covered by the media, the distribution of incentives across list ranks is bell-shaped, as shown in Crutzen, Flamand and Sahuguet (2020). The position on the list that corresponds to the expected number of seats the party will win in the election leads to the strongest incentives to exert effort. As effort is increasing in competence, all else equal, parties assign their most competent candidate to that position on the list, and then rank candidates around that position in decreasing order of competence. Thus, these bell-shaped incentives push parties 
to adopt a ranking that mirrors these incentives when their candidates differ in competence.

This finding does not change when candidates are also driven by ideology, as the impact of ideology on effort is independent of the position on the list. That ideology has no impact on the way parties rank their candidates to maximize electoral success also has the following, surprising additional effect. Ideological polarization only impacts candidates' objective function via the payoff linked to ideology. As ideology impact on incentives does not depend on the rank on the party list, changes in the ideological polarization do not influence how parties rank candidates.

Post-electoral high offices (typically linked to the control of the executive) offer a possible avenue to explain why we observe parties rank candidates in decreasing order of competence. If candidates ranked at the top of the list can get access to a high office, candidates get an additional motivation to exert effort to get their party win a majority of seats. If these additional incentives are strong enough, they can overturn the bell-shaped incentives coming from the prospect of winning a seat in parliament. Parties may then find it optimal to rank candidates in order of decreasing competence.

The presence of media effects adds to the above findings. Indeed, it is well documented that the media coverage of candidates differs based on their position on the list. Existing evidence suggests that candidates at the top of the list receive more attention than those lower on the list, with candidates who sit in hopeless positions receiving no attention at all (see for example Tresch (2009); Van Aelst, Sehata, and Van Dalen (2010); or Vos and Van Aelst (2018)). Indeed, whenever parties have to comment on a policy issue or need to send in a representative to participate in a debate, the media want their top candidates. In particular, the candidate who is at the top of the list receives the bulk of all media attention. These media effects imply that candidates at the top of the list have a stronger impact on voters. Top candidates become the essential input of the party's electoral output. This reinforces parties' incentives to rank their candidates in decreasing order of competence, to have their most competent representatives receive the bulk of media attention, which in turn pushes these top candidates to exert highest effort. 


\section{Related Literature}

Candidate ranking strategies are not well understood in closed-list proportional representation systems, especially when both incentive and competence considerations play a role. Our paper thus adds to a small but growing literature, both empirical and theoretical, that focuses on the effects of closed party lists and their composition on electoral outcomes. Cox et al. (2020), Crutzen et al. (2020) and Crutzen and Sahuguet (2020) also focus on the incentives effects of the list composition. They show how also the list order can help solve the moral hazard in teams problem that is created by closed-lists. Buisseret et al. (2019) also consider the impact of the list order on electoral success, but focus on competence. ${ }^{3}$

Cox et al. (2020) study Norwegian data covering the 2017 parliamentary election. They document empirically that candidates' quality increases with their position on the list, and the rank on the list influences effort provision on several dimensions. In particular, highly ranked candidates tend to spend relatively more effort on extra-district campaigning than on intra-district campaigning. They also document how media coverage varies with the position on the list. They develop a formal model to analyze the conditions under which candidates decide to spend their effort to influence constituents at the local or national level. In contrast with our analysis, parties' optimal candidate ranking strategy follows from the differences in the cost of effort and does not take into account the difference in incentives linked with the position on the list.

Crutzen and Sahuguet (2020) analyze the interaction between the competitiveness of parties' candidate selection procedures and electoral systems - contrasting British-style first past the post and Israeli-style proportional representation - and show that the way parties select candidates may impact candidate incentives more strongly than the electoral system itself. Yet, in that model, candidates also do not differ in competence.

Our theory builds on Crutzen et al. (2020). Compared to that paper, we extend the model along three dimensions. We introduce candidate heterogeneity in the cost of effort. This allows for a meaningful analysis of the impact of list order on incentives. We also enrich the payoffs of candidates: we add an ideological payoff that is independent of the

\footnotetext{
${ }^{3}$ Other, less closely related contributions include Shugart et al. (2005), Hobolt and Hoyland (2011), Caroll and Nalepa (2020) and Buisseret and Prato (forthcoming).
} 
position on the list and an individual payoff - linked to post-electoral high offices - that varies according to the position on the list. Finally, we introduce media weights in the party output production function. These weights are decreasing with rank. Tresch (2009); Van Aelst et al. (2010); or Vos and Van Aelst (2018) report evidence that corroborates this assumption.

Buisseret et al. (2019) also propose a formal model of list composition and then test their predictions on Swedish municipal election data. Their model focuses on competence and leaves aside incentive effects. Candidates differ in competence and are passive participants in the electoral contest. ${ }^{4}$ The outcome of the election is determined by a complex calculus of voting. As in our model, parties that want to maximize their electoral success place their best candidates on marginal ranks. Yet, this is not due to incentive reasons, but to the fact that "a voter recognizes that her vote is likely to be inconsequential for the election prospects of candidates located within safe ranks" (Buisseret et al., 2019, p. 2). If parties also care about electing their best candidates and voters "recognize that high-quality leaders are the primary drivers of good policy outcomes" (p. 14), then placing the best candidates at the top of the list can be optimal.

Our theoretical predictions also help refine the empirical studies in the field. Indeed, we are not aware of any theoretical prediction on the effect of the media and the importance of post-electoral high offices on candidates' ranking strategies of parties. For example, some contributions focus on the role of gender (Baltrunaite, Bello, Casarico and Profeta, 2014; Esteve-Volart and Bagues, 2012; Besley, Folke, Persson and Rickne, 2017). Others show that party loyalty matters, as Galasso and Nannicini (2015) do for the 2015 Italian elections (and especially for safe seats). Matakos, Savolainen, Troumpounis, Tukiainen and Xefteris (2018) show that parties value more and thus select a more diverse set of candidates in elections in which the electoral formula is more proportional. Using historical Norwegian data since 1945, Cirone, Cox and Fiva (2020) find that incumbency and seniority matter for party nomination strategies. Some studies do find that competence is a key driver of the way parties rank candidates. Dal Bo et al. (2017), for Sweden, Cox et al. (2020), for Norway,

\footnotetext{
${ }^{4}$ Matakos, Savolainen, Troumpounis, Tukiainen and Xefteris (2018) develop a related model in which candidates are also passive actors. They focus on the trade-off between the ideological cohesion of a party list and the breadth of its electoral appeal.
} 
and Svitakova and Soltes (2020), for the Czech republic, find that candidate competence (as measured by earnings score or years of education) correlates positively with list rank, implying that parties put their best candidates at the top of their list. But in none of these works the role of media coverage and post-electoral job opportunities are taken into explicit consideration.

\section{The model}

Candidates and parties. Two parties are competing for $n$ (odd) legislative seats. ${ }^{5}$ Party $j$ fields a list of $n$ candidates who exert effort to contribute to their party electoral success. Candidate $i$ in party $j$ exerts effort $e_{i j}$ at quadratic cost $K_{i j}\left(e_{i j}\right)=\frac{1}{2} c_{i j} e_{i j}^{2}$. Candidates thus differ in their cost of effort. We interpret this heterogeneity in costs as heterogeneity in the competence of candidates. A list for party $j$ is a mapping $\alpha_{j}:\{1, \ldots, n\} \rightarrow\{1, \ldots ., n\}$ that assigns position $m$ on the list to candidate $i$. Parties maximize their electoral success: the list is designed by the party leadership to maximize the number of legislative seats won in the election. Given a list $\alpha_{j}$, it is convenient to call candidate $i$ in position $m$ on party $j^{\prime}$ s list $\left(\alpha_{j}(m)=i\right)$ by her position $m_{j}$. When parties choose their list, we will be more precise with notation.

Party $j$ 's electoral output, the quality of its electoral platform as perceived by voters, is the weighted sum of its candidates' efforts:

$$
E_{j}=\sum_{m=1}^{n} a_{m} e_{m j}
$$

where the vector of weights $\mathbf{a}=\left(a_{1}, a_{2}, \ldots, a_{n}\right)$ is due to media effects. The media may disproportionately report on the actions of candidates who are ranked high on the list. Therefore, we set $a_{1}=1$ and all other $a_{m}$ 's are weakly decreasing in the position on the list $m .^{6}$

Election. The number of legislative seats won by party $j$ is a random variable. The distribution of the number of seats is assumed to follow a multinomial distribution. The

\footnotetext{
${ }^{5}$ The analysis can be extended to a larger number of parties.

${ }^{6}$ Note that we assume that the weights are the same in all parties, as it is the media that determine these.
} 
parameter of the distribution is determined in a generalized Tullock contest among the parties based on the ratios of parties' electoral outputs. Party j's probability of winning each seat follows a binomial distribution described by each seat's winning probability $p_{j}{ }^{7}$

$$
p_{j}=\frac{\left(E_{j}\right)^{\gamma}}{\left(E_{j}\right)^{\gamma}+\left(E_{-j}\right)^{\gamma}},
$$

where $\gamma$ is a return to scale parameter, and $-j$ denotes the other party. Values of $\gamma$ lower than 1 make the allocation of prizes among teams more noisy and less responsive to parties' outputs. Lower values of $\gamma$ also make the objective functions of team members more concave; $\gamma$ thus plays an important role to ensure equilibrium existence.

We assume that the probabilities of winning seats are independent. Thus, the probability of party $j$ 's winning $k$ seats is given by:

$$
P_{j}^{k}=C_{k}^{n} p_{j}^{k}\left(1-p_{j}\right)^{n-k}
$$

Payoffs. On the cost side, we already mentioned that candidate $i$ 's individual effort cost is $K\left(e_{m j}\right)=\frac{1}{2} c_{m j} e_{m j}^{2}$. There is a benefit to be elected to the legislature, equal to $V$. Candidate in position $m$ on the list gets elected if the party wins at least $m$ seats, which happens with probability $\sum_{k=m}^{n} P_{j}^{k}$.

Each candidate also enjoys a purely ideological benefit $W$ when their party wins a majority of legislative seats, as it then controls the executive and can implement its platform. The party wins such a majority of $k^{m a j}=\frac{n+1}{2}$ seats with probability $\sum_{k=k^{m a j}}^{n} P_{j}^{k}$.

When the party wins the election, the top candidates of each party may gain access to an executive position or some other high office, such as the position of House Speaker. We assume that there are $k^{C} \leq \frac{n+1}{2}$ such executive positions and high offices and that these positions go to the candidates ranked in the top $k^{C}$ slots on the party list, with the candidate in position $m\left(<k^{C}\right)$ receiving the office with $m^{\text {th }}$ highest value. Thus, these offices each have value $w_{m}$ and $w_{1} \geq w_{2} \geq . . \geq w_{k^{C}} \geq w_{k^{C}+1}=\ldots=w_{n}=0$. Let $W_{m}=W+w_{m}$.

\footnotetext{
${ }^{7}$ Our modelling strategy allows for the inclusion of a weight $\rho>1$ multiplying party $j$ 's output. These weights introduce a bias in the contest as one party is advantaged, possibly due to voters' ideology leaning towards that party. The probability $p_{j}$ then becomes $p_{j}=\frac{\left(\rho E_{j}\right)^{\gamma}}{\left(\rho E_{j}\right)^{\gamma}+\left(E_{-j}\right)^{\gamma}}$. For the sake of expositional clarity, we do not add these weights in what follows.
} 
Candidate $m j$ in position $m$ on party $j$ 's list has thus the following benefit function:

$$
B_{m j}=V \sum_{k=m}^{n} P_{j}^{k}+W_{m} \sum_{k=k^{m a j}}^{n} P_{j}^{k}
$$

\section{Timing}

The timing of the game is as follows.

1- Nomination stage: Party leadership designs the list of candidates.

2- Campaign stage: Given party lists, candidates exert effort.

3- Election stage: Given perceived party outputs, seats are allocated to parties.

\section{Solving the model}

\subsection{Campaign stage: equilibrium efforts}

In this subsection, we solve for the equilibrium of the campaign stage in which candidates choose effort given the party lists and their position on their party list. Candidates exert

effort to increase the probability they get elected (simply to parliament or to parliament and a higher office) through an increase in $p_{j}$. Candidate in position $m$ in party $j$ chooses effort $e_{m j}$ to maximize:

$$
\begin{aligned}
& B_{m j}-K_{m j}\left(e_{m j}\right) \\
= & V \sum_{k=m}^{n} P^{k}\left(p_{j}\right)+W_{m} \sum_{k=k^{m a j}}^{n} P^{k}\left(p_{j}\right)-\frac{1}{2} c_{m j}\left(e_{m j}\right)^{2} .
\end{aligned}
$$

Let $M_{j}^{m}=m C_{m}^{n} p_{j}^{m}\left(1-p_{j}\right)^{n-m+1}$ and $M_{j}^{m a j}=k^{m a j} C_{k^{m a j}}^{n} p_{j}^{k^{m a j}}\left(1-p_{j}\right)^{n-k^{m a j}+1}$. We then have:

Proposition 1. In the Nash equilibrium of the game, candidate in position $m$ on the list of 
party $j$ exerts effort $e_{m j}^{*}$ and party $j$ 's electoral output is given by $E_{j}^{*}$, where:

$$
\begin{aligned}
e_{m j}^{*} & =\frac{\gamma a_{m}}{c_{m j} E_{j}^{*}}\left(M_{j}^{m} V+M_{j}^{m a j} W_{m}\right), \\
E_{j}^{*} & =\sqrt{\sum_{m=1}^{n} \gamma \frac{a_{m}^{2}}{c_{m j}}\left(M_{j}^{m} V+M_{j}^{m a j} W_{m}\right)} .
\end{aligned}
$$

Proof. See appendix

We characterize the equilibrium by taking the first-order conditions of candidates' maximization problems. In the appendix, we also check the second-order conditions and derive a sufficient condition under which the solution of the system of first-order conditions indeed maximizes candidates' expected payoff.

If all candidates were of equal competence, the distribution of equilibrium efforts would follow the distribution of $a_{m}^{2}\left(M_{j}^{m} V+M_{j}^{m a j} W_{m}\right)$. As the distribution of binomial coefficients is bell-shaped, the distribution of effort inherits similar features (see Crutzen et al., 2020 for more details on the case with no media effect and $\left.W_{m}=0\right)$. When candidates are heterogeneous in competence, equilibrium efforts also depend on how competence maps into parties' candidate ranking strategy.

\subsection{Nomination stage}

Given the above optimal choices of candidates, parties order candidates on their list to maximize their electoral success. In doing so, parties take into account the equilibrium efforts defined in Eq.(2) and (3) as well as the associated probabilities of winning seats. Party $j$ 's equilibrium electoral output $E_{j}^{*}=\sqrt{\sum_{m=1}^{n} \gamma \frac{a_{m}^{2}}{c_{m j}}\left(M_{j}^{m} V+M_{j}^{m a j} W_{m}\right)}$ depends on the weights $M_{j}^{m}$ and $M_{j}^{m a j}$, which are themselves a function of $p_{j}$. The party thus assigns candidates with marginal costs of effort $c_{m j}$ to a position in which the incentive to exert effort is proportional to $\Lambda_{j}^{m}\left(p_{j}\right)=a_{m}^{2}\left(M_{j}^{m} V+M_{j}^{m a j} W_{m}\right)$. To maximize party output, the list should assign the highest quality candidates to the position with the highest value of $\Lambda_{m}$, the second highest quality candidate to the the position with the second highest value of $\Lambda_{j}^{m}$, and so on and so forth. 
Note that the previous argument assumes a fixed expected probability $p_{j}$. However, a change in the order in the list leads to a subgame with different efforts and a different equilibrium probability $p_{j}$. We derive in the appendix a regularity condition that guarantees that, when a party chooses a ranking of candidates that increases $E_{j}$, this choice also leads to an increase in the equilibrium probability of winning a seat. Under this condition, we have:

Theorem 2. Parties order candidates according to the $\Lambda_{j}^{m}$, associating the most competent candidates to the positions with the highest value of $\Lambda_{j}^{m}$. Thus, the optimal list $m_{j}^{*}$ assigns the candidate with the lowest cost of effort to the position with the highest value of $\Lambda_{j}^{m}$ and orders all other candidates around this top candidate in decreasing order of competence. This strategy maximizes party aggregate effort and winning probability.

To rank candidates, parties need to consider carefully the $M_{j}^{m}$ function, as $\Lambda_{j}^{m}$ is increasing in $M_{j}^{m}$, given that $\Lambda_{j}^{m}=a_{m}^{2}\left(M_{j}^{m} V+M_{j}^{m a j} W_{m}\right)$ and $M_{j}^{m a j}$ is constant across slots on

the list. Remember that $M_{j}^{m}=m C_{m}^{n} p_{j}^{m}\left(1-p_{j}\right)^{n-m+1}$. Then, $M_{j}^{m}$ is always strictly positive and it is straightforward to show that $M_{j}^{m} \gtreqless M_{j}^{m+1}$ if and only if $(n+1) p_{j} \gtreqless m$. Finally, the distribution of $M_{j}^{m}$ is single-peaked at $m=\left\lfloor(n+1) p_{j}\right\rfloor$, where $\left\lfloor(n+1) p_{j}\right\rfloor$ is the smallest integer greater than $(n+1) p_{j}-1$ in case $(n+1) p_{j}$ is not an integer itself.

\section{Optimal list ordering}

We now apply the theorem to analyze how the different elements of the model map into different list ordering strategies. In particular, we identify scenarios that lead to ranking candidates in decreasing order of competence.

\subsection{No media effects and no executive positions}

We start with the simplest case: candidates only care about the benefit $V$ of being elected to the legislature; there are no executive positions available, $w_{m}=0$; candidates are not ideological $(W=0))$; and, finally, the media devote the same attention to all candidates, that is, $a_{i}=1$ for all $i$. These assumptions imply that $\Lambda_{j}^{m}=M_{j}^{m} V$. 
To maximize their party's electoral success, the leadership assigns the most competent candidate to the position with the highest value of $M_{j}^{m}$. As the distribution of weights $M_{j}^{m}$ is hump-shaped and single-peaked, the distribution of competence across ranks needs to replicate this hump-shape, with the most competent candidate in position $n p_{j}+1$, if we ignore integer constraints. Indeed, if the party expects to win $n p_{j}$ seats, then the marginal benefit of exerting effort is highest for the candidate who is exactly at $n p_{j}+1$. More generally, other candidates are allocated in positions around the peak in decreasing order of competence following the values of $M_{j}^{m}$. We thus have:

Proposition 3. Expected seat share hypothesis. When candidates only care about getting a seat in parliament and the media treat all candidates equally, parties assign positions on the list so that the distribution of competence across ranks is hump-shaped, with the most competent candidate in position $\left\lfloor n p_{j}+1\right\rfloor$, the position corresponding to party $j$ 's equilibrium expected seat share.

Proof. See appendix.

The intuition behind Proposition 3 is simple. Candidates at the bottom and at the top of the party's list are respectively in hopeless and safe spots and face weak incentives to exert effort. Indeed their effort has a tiny impact on the party's output. To the contrary, candidates at a position close to the expected number of seats that the party will win, face powerful incentives to exert effort. Indeed, in equilibrium, the party is expected to win $n p_{j}$ seats. Candidates with a rank around this number have the most to gain from an increase in the party's output. So, a small change in effort can be decisive in getting the candidate a seat in parliament. The party's optimal strategy is then to allocate its best candidates at and around the list position corresponding to the number of seats it expects to win. Parties thus distribute candidates around position $\left\lfloor n p_{j}+1\right\rfloor$ in decreasing order of competence. Competence corresponds to a smaller effort cost and thus more competent candidates exert more effort than less competent ones for any given incentive. The important implication of the "expected seat share hypothesis" is that candidates placed at the top of the list are not the most competent ones.

Turning to the effect of ideology, $W$, we have: 
Proposition 4. The ideological benefit $W$ has no effect on parties' optimal list strategies.

An increase in ideological motivation, caused for example by an increase in the polarization of party platforms, makes the stakes of the election higher. Intuition would then suggest that parties have stronger incentives to put their best candidates on top of the list. This intuition turns out to be incorrect. The benefit $W$ impacts party output through $M_{j}^{m a j} W$. Therefore, as $M_{j}^{m a j}$ is the same for all candidates, a change in $W$ does not affect the ranking of the $M_{j}^{m} V+M_{j}^{m a j} W$, and thus the optimal list order does not depend on $W$. The recent increases in polarization witnessed in many if not most democracies have several effects on elections and politics. Our model predicts that the way parties rank their candidates should not be one of them.

To wrap up on our findings so far, parties are predicted not to rank candidates in decreasing order of competence if candidates' main motivation is to get elected to parliament or to see their party implement its manifesto.

\subsection{The role of executive positions linked to the party winning a majority}

In most democracies, the party winning the election usually controls the executive and has access to other high offices, such as the House Speaker. It is also customary for parties to offer these positions and offices to their top candidates. This means that the prize promised to the top candidate of a party's list when the party wins the majority is typically of higher value than the prize promised to the second highest candidate on that list, and so on and so forth.

We investigate how such prizes impact our previous findings (we still ignore media effects). We know from Proposition 3 that the prospect of being elected to parliament gives top and bottom candidates on the list little to no incentives to exert effort.

Yet, for top candidates, once executive positions and other high offices become likely this likelihood is obviously increasing in the electoral strength of their party (the value $p_{j}$ takes on in equilibrium) - these prizes generate additional incentives to exert effort. These additional incentives are decreasing in rank, so that they offer the largest boost to the 
candidate at the top of the list, the second largest boost to the second candidate on the list, and so on. If the value of these additional prizes is large enough, the incentives they generate can be sufficiently strong for the party to rank candidates in decreasing order of competence. The next proposition formalizes this argument.

Proposition 5. Effect of executive and higher offices on party strategy. A necessary condition for party $j$ to rank candidates in decreasing order of competence is that for all $m \leq k^{C},\left(W_{m}-W_{m+1}\right) \geq \frac{V}{M^{M a j}}\left(M_{j}^{m+1}-M_{j}^{m}\right)$. If $k^{c} \geq\left\lfloor n p_{j}+1\right\rfloor$, then another condition is needed $W_{k^{c}} \geq \frac{V}{M^{M a j}}\left(M_{j}^{\left\lfloor n p_{j}+1\right\rfloor}-M_{j}^{k^{c}}\right)$.

Proof. If the first condition is satisfied, then $\Lambda_{j}^{m} \geq \Lambda_{j}^{m+1}$ and incentives are decreasing at the top of the list. If $k^{c} \geq\left\lfloor n p_{j}+1\right\rfloor$, then $\Lambda_{j}^{m}$ is decreasing for all $m \geq k^{c}$ as $M_{j}^{m}$ is decreasing for $m \geq\left\lfloor n p_{j}+1\right\rfloor$. If $k^{c} \leq\left\lfloor n p_{j}+1\right\rfloor$, the second condition states that the incentives of the last candidate on the list who can win a high office who is in poistion $k^{c}$ are larger than those of the candidate in position $\left\lfloor n p_{j}+1\right\rfloor$ for which $M_{j}^{m}$ is maximal.

Thus, provided that executive positions and high offices generate strong enough incentives, parties optimally rank candidates in decreasing order of competence. Remark that this is the case even though in our model parties only care about their electoral success. Of course, if parties also care about the competence of their candidates elected to parliament and put in executive psoitions, they would have additional reasons to rank candidates in decreasing order of competence.

\subsection{The role of media attention}

Tresch (2009) reports that media exposure is increasing in the importance of a candidate within their party (measured in terms of parliamentary activity), with leaders receiving the greatest exposure. A similar conclusion is reached by Van Aelst, Sehata and Van Dalen (2010), which shows that media exposure grows with the importance of a candidate in terms of experience and their institutional position. Finally, Vos and Van Aelst (2018) show that this bias in media exposure towards the most prominent politicians is observed across all political systems, with media exposure in a country tracking quite closely the political hierarchy that is determined by the political system of that country. 
Building on these facts, we now allow media weights to be decreasing in list rank. Then, media weights are another countervailing force to the non-monotonic incentives generated by the prospect of getting elected. Indeed, when media exposure is biased towards the parties' top candidates, voters' perception of the parties' electoral outputs becomes much more dependent on the choices of those top candidates. In that case, parties may find it in their interest to rank candidates in decreasing order of competence. This happens if the media weights decrease sufficiently fast with rank, that is, if media exposure is biased towards top candidates severely enough. The next proposition formalizes this finding.

Proposition 6. Media exposure effects on party strategy. Suppose candidates only care about getting a seat in parliament $\left(W_{m}=0\right)$ and media exposure is biased towards parties' top candidates. Then, parties rank candidates on their lists in decreasing order of competence when media weights are such that, for any $j, a_{m} \geq \sqrt{\frac{(n-m)}{m} \frac{p_{j}}{1-p_{j}}} a_{m+1}$.

Proof. Applying theorem 2, parties optimally rank candidates in decreasing order of competence if $\Lambda_{j}^{m} \geq \Lambda_{j}^{m+1}$ for all $m$. Recall that $\Lambda_{j}^{m}=a_{m}^{2} M_{j}^{m} V=a_{m}^{2}\left(m C_{m}^{n} p_{j}^{m}\left(1-p_{j}\right)^{n-m+1}\right) V$. Rearranging leads directly to the above condition.

Our final prediction is therefore that parties will rank candidates in decreasing order of competence if the media are sufficiently biased towards parties' top candidates, even when these candidates only care about getting a seat in the legislature.

Intuition suggests that voters should benefit from the media covering uniformly the decisions and choices of all candidates in an election. Our theory suggests a positive side effect of media biases towards the top candidates as it leads parties to place their best candidates at the top of their list. Such lists ensure that elected politicians are those of highest competence and may turn out to better from a welfare perspective than a policy ensuring full, unbiased media coverage of all candidates. Of course, when the objective function of top candidates also includes the benefits from their party winning a majority of seats, the incentives for parties to rank candidates in decreasing order of competence become even stronger. 


\subsection{Party's popularity and list order}

In most countries relying on proportional representation, a wide array of parties compete for seats. Some of them are major parties looking to win control of or at least participate in government, while other smaller parties are trying to push their agenda and get a few seats without a real chance to control the executive. Does the party's popularity and expected seat share influence the way they organize their list and rank their candidates? In the model, $p_{j}$ corresponds to party $j$ 's popularity. Of course, the vector of $p_{j}$ 's is endogenous and determined in equilibrium, but these probabilities also reflect the competence of parties' candidates. We now discuss how the ranking of candidates on the list and the popularity of the party go together.

In proposition 3, we saw that a party would place their most competent candidate around the position corresponding to the expected number of seats. Thus, on average, under the conditions of proposition 3, small parties will place their best candidates earlier on their list than more popular parties. For instance, a party that expects to send only one candidate to the parliament will place its best candidate at the top of the list.

The effects of high offices discussed above depend on the value of $M^{m a j}\left(p_{j}\right)$. The condition in proposition 5 is more easily met for higher values of $p_{j}$, that is for strong parties that are expected to win a large number of seats in parliament. Indeed, the effects of high offices are proportional to the probability that the party wins a majority. Thus, it is in large parties that the effects of high offices on incentives play an important role. As in the case analyzed above, electorally strong parties are thus more likely than weak parties to rank candidates in decreasing order of competence.

Media effect also have a different impact depending on the electoral strength of the party.

The condition from proposition $6, a_{m} \geq \sqrt{\frac{(n-m)}{m} \frac{p_{j}}{1-p_{j}}} a_{m+1}$, depends on the ratio $\frac{p_{j}}{1-p_{j}}$ which is increasing in $p_{j}$. This means that the media effect needs to be stronger in electoral strong parties. 


\section{Conclusion}

We develop a model of electoral competition between parties under closed list proportional representation. Parties care about competence and incentives. A party orders its candidates on their list to maximize the efforts of its candidates. We identify three main sources of incentives. The first incentive to exert effort come from the prospect of being elected to parliament. These incentives depend non-monotonically on the position of the list. Incentives are most powerful for hot spots that correspond to the number of seats that the party expects to win in the election. Incentives are weak for safe and hopeless spots, that correspond to the top and the bottom of the list. The second source of variation in incentives comes from the prospect for high-ranked candidates to get executive position after the election when the party wins a majority. The third source comes from the media and how they bias their attention towards candidates at the top of the list leveraging the impact of their effort. We show that parties need to place their best candidates to positions that leads to the strongest incentives. As the first source of incentives is non-monotonic while the other two sources are decreasing in position, the optimal list can take various forms depending on the relative importance of these incentives.

We assume in this paper that parties are designing the list to maximize their electoral success. Parties may also be interested in getting the best candidates elected. In that case, it is natural for the party to put their most competent candidates at the top of the list. Our results show that these two objectives need not be contradictory and that a list that orders

candidates in decreasing order of competence can be consistent with both objectives, and thus with any alternative party objective that takes into account both the expected number of seats and the quality of elected candidates. 


\section{$7 \quad$ References}

Baltrunaite, A., Bello, P., Casarico, A., \& Profeta, P. (2014). Gender quotas and the quality of politicians. Journal of Public Economics, 118, 62-74.

Besley, Timothy, Olle Folke, Torsten Persson, and Johanna Rickne. (2017). "Gender Quotas and the Crisis of the Mediocre Man: Theory and Evidence from Sweden". American Economic Review 107: 2204-2242

Buisseret, Peter and Carlo Prato (forthcoming). "Competing Principals? Legislative Representation in List Proportional Representation Systems," American Journal of Politicial Science.

Buisseret, Peter, Olle Folke, Carlo Prato and Johanna Rickne (2019). "Party Nomination Strategies in List Proportional Representation systems," mimeo University of Chicago School of Public Policy.

Carroll, Royce, and Monika Nalepa. "The personal vote and party cohesion: Modeling the effects of electoral rules on intraparty politics." Journal of Theoretical Politics 32.1 (2020): 36-69.

Cirone, Alexandra, Gary W. Cox, and Jon H. Fiva, (2021). "Seniority-based nominations and political careers." American Political Science Review. 115(1): 234-251.

Cox, Gary, Jon Fiva, Daniel Smith and Rune Sorensen (2020). "Moral Hazard in electoral teams.", mimeo.

Crutzen, Benoit S Y, Sabine Flamand and Nicolas Sahuguet (2020). "Prize allocation and incentives in team contests", Journal of Public Economics, 182(C).

Crutzen, Benoit S Y and Nicolas Sahuguet (2020). "Comparative Politics with Intraparty Candidate Selection," CEPR Discussion Paper No. DP14763.

Cruz, Cesi, Philip Keefer and Carlos Scartascini, (2018). "The Database of Political Institutions 2017". Inter-American Development Bank. https://publications.iadb.org/handle/11319/8806

Dal Bó Ernesto , Frederico Finan, Olle Folke, Torsten Persson, Johanna Rickne, (2017). "Who Becomes A Politician?", The Quarterly Journal of Economics, 132(4), 1877-1914.

Esteve-Volart, Berta, and Manuel Bagues,(2012). "Are women pawns in the political game? Evidence from elections to the Spanish Senate." Journal of Public Economics 96(3- 
4): 387-399.

Galasso, Vincenzo, and Tommaso Nannicini, (2015). "So closed: Political selection in proportional systems." European Journal of Political Economy, 40: 260-273.

Hobolt, Sara B., and Bjørn Høyland, (2011). "Selection and sanctioning in European parliamentary elections." British Journal of Political Science. 477-498.

Matakos Konstantinos, Riikka Savolainen, Orestis Troumpounis, Janne Tukiainen, Dimitrios Xefteris (2018). Electoral institutions and intraparty cohesion. Working paper.

Shugart, M. S., Valdini, M. E., \& Suominen, K. (2005). Looking for locals: Voter information demands and personal vote-earning attributes of legislators under proportional representation. American Journal of Political Science, 49(2), 437-449.

Svitakova Klara and Michal Soltes, 2020. "Sorting of Candidates: Evidence from 20,000 Electoral Ballots," CERGE-EI Working Papers wp652, The Center for Economic Research and Graduate Education - Economics Institute, Prague.

Tresch, A. (2009). Politicians in the Media: Determinants of Legislators' Presence and Prominence in Swiss Newspapers. The International Journal of Press/Politics, 14(1), 67-90.

Tullock, Gordon (1980). "Efficient rent-seeking." in J.M. Buchanan, R.D. Tollison and G. Tullock (eds.) Toward a theory of the rent-seeking society. College Station Texas A\&M Press.

Van Aelst Peter, Adam Sehata and Arjen Van Dalen (2010). "Members of Parliament: Equal Competitors for Media Attention? An Analysis of Personal Contacts Between MPs and Political Journalists in Five European Countries." Political Communication. 27, 310325.

Vos, Debby, and Peter Van Aelst, (2018). "Does the political system determine media visibility of politicians? A comparative analysis of political functions in the news in sixteen countries." Political Communication 35(3): 371-392. 


\section{Appendix}

\section{Proof of proposition 1}

Candidate $m_{j}$ exerts effort to increase the probability he gets elected through an increase in $p_{j}$.

The impact of an increase in that candidate $m_{j}$ 's effort on party $j$ 's aggregate effort is:

$$
\frac{\partial E_{j}}{\partial e_{m j}}=a_{m}
$$

thus, the impact of an increase in $e_{m j}$ on $p_{j}$ is:

$$
\begin{aligned}
\frac{\partial p_{j}}{\partial e_{m j}} & =a_{m} \frac{\left(E_{-j}\right)^{\gamma-1}}{\left(\left(E_{-j}\right)^{\gamma}+\left(E_{j}\right)^{\gamma}\right)^{2}} \\
& =\gamma \frac{a_{m}}{E_{j}} p_{j}\left(1-p_{j}\right) .
\end{aligned}
$$

Differentiating $P^{k}\left(p_{j}\right)$, we obtain:

$$
\begin{aligned}
\frac{d P^{k}}{d p_{j}} & =C_{k}^{n}\left(k p_{j}^{k-1}\left(1-p_{j}\right)^{n-k}-(n-k) p_{j}^{k}\left(1-p_{j}\right)^{n-k-1}\right) \\
& =C_{k}^{n} p_{j}^{k-1}\left(1-p_{j}\right)^{n-k-1}\left(k-n p_{j}\right) .
\end{aligned}
$$

Notice that the sign of the above is not always positive. This can be seen by noting the special case of $k=0$. If $p_{j}$ increases, it is obvious that $P^{0}\left(p_{j}\right)$ is decreasing. As the above formula shows, $\frac{d P^{k}}{d p_{j}} \gtreqless 0$ if and only if $k \gtreqless n p_{j}$.

So we get:

$$
\frac{d P^{k}}{d e_{m j}}=\gamma \frac{a_{m}}{E_{j}} C_{k}^{n} p_{j}^{k}\left(1-p_{j}\right)^{n-k}\left(k-n p_{j}\right)
$$

Denoting $\mu_{j}^{k}=C_{k}^{n} p_{j}^{k}\left(1-p_{j}\right)^{n-k}\left(k-n p_{j}\right)$, we have:

$$
\frac{d P^{k}}{d e_{m j}}=\gamma \frac{a_{m}}{E_{j}} \mu_{j}^{k}
$$


We obtain

$$
\begin{gathered}
\frac{\partial B_{m j}}{\partial e_{m j}}-\frac{\partial K\left(e_{m j}\right)}{\partial e_{m j}}=\gamma \frac{a_{m}}{E_{j}}\left(V \sum_{k=m}^{n} \mu_{j}^{k}+W_{m} \sum_{k=k^{M a j}}^{n} \mu_{j}^{k}\right)-c_{m j} e_{m j}=0 . \\
E_{j}=\sum_{m=1}^{n} a_{m} e_{m j}=\sum_{m=1}^{n} a_{m} \frac{\gamma a_{m}}{c_{m j} E_{j}}\left(V \sum_{k=m}^{n} \mu_{j}^{k}+W_{m} \sum_{k=k^{M a j}}^{n} \mu_{j}^{k}\right) .
\end{gathered}
$$

Let $\sum_{k=m}^{n} \mu^{k}=M_{j}^{m}$. We have

$$
M_{j}^{m}=m C_{m}^{n} p^{m}(1-p)^{n-m+1} .
$$

Thus, the equilibrium sum of efforts is

$$
E_{j}^{*}=\sqrt{\sum_{m=1}^{n} \gamma \frac{a_{m}^{2}}{c_{m j}}\left(M_{j}^{m} V+M_{j}^{k^{M a j}} W_{m}\right)},
$$

and individual effort is given by:

$$
e_{m j}=\frac{\frac{\gamma a_{m}}{c_{m j}}\left(V M_{j}^{m}+W M_{j}^{k^{M a j}}\right)}{\sum_{h=1}^{n} \frac{\gamma a_{h}^{2}}{c_{h j}}\left(V M_{j}^{m}+W M_{j}^{k^{M a j}}\right)} .
$$

To check second order conditions, we take the second derivative and evaluate them at the FOC. We have:

$$
\begin{aligned}
& \frac{\partial^{2} B_{m j}}{\partial e_{m j}^{2}}-c^{\prime \prime}\left(e_{m j}\right) \\
= & -\frac{\gamma a_{m}^{2}}{E_{j}^{2}}\left(V M_{j}^{m}+W_{m} M_{j}^{k^{M a j}}\right)+\frac{\gamma a_{m}}{E_{j}} \frac{d\left(V M_{j}^{m}+W_{m} M_{j}^{k^{M a j}}\right)}{d p_{j}} \frac{d p_{j}}{d e_{m j}}-c_{m j} \\
= & -\frac{\gamma a_{m}^{2}}{E_{j}^{2}}\left(V M_{j}^{m}+W_{m} M_{j}^{k^{M a j}}\right)+\frac{\gamma^{2} a_{m}^{2}}{E_{j}^{2}}\left(V M_{j}^{m}\left(m\left(1-p_{j}\right)-(n-m+1) p_{j}\right)+W_{m} M_{j}^{k^{M a j}} k^{M a j}\left(1-p_{j}\right)\right. \\
& -\frac{\gamma a_{m}}{e_{m j} E_{j}}\left(V M_{j}^{m}+W M_{j}^{k^{M a j}}\right) \\
= & \frac{\gamma}{e_{m j}} \frac{a_{m}}{E_{j}} V M^{m}\left(p_{j}\right)\left[\theta_{m j}\left\{\gamma\left(m\left(1-p_{j}\right)-(n-m+1) p_{j}\right)-1\right\}-1\right] \\
& +\frac{\gamma}{e_{m j}} \frac{a_{m}}{E_{j}} W_{m} M^{k^{M a j}}\left(p_{j}\right)\left[\theta_{m j}\left\{\gamma\left(k^{M a j}\left(1-p_{j}\right)-\left(n-k^{M a j}+1\right) p_{j}\right)-1\right\}-1\right]
\end{aligned}
$$


where

$$
\theta_{m j}=a_{m j} \frac{e_{m j}}{E_{j}} .
$$

The sign of $\theta_{m j}\left\{\gamma\left(m\left(1-p_{j}\right)-(n-m+1) p_{j}-1\right\}-1\right.$ needs to be determined.

We have:

$$
\gamma\left(m\left(1-p_{j}\right)-(n-m+1) p_{j}\right)-1=\gamma\left(m-(n+1) p_{j}\right)-1
$$

As the expression is increasing in $m$ and decreasing in $p_{j}$, a sufficient condition for the expression to be negative for all $m$ is that $\gamma<1 / n$ (by having $m=n$ and $p_{j}=0$ ). This condition is not necessary and second order conditions can be satisfied even for values of $\gamma$ close to 1 . We also see that if the expression is negative for $m=k^{M a j}=(n+1) / 2$, then an increase in $W_{m}$ increases the relative importance of the second term. So, in that case a large $W_{m}$ leads to the SOC be satisfied even for larger values of the parameter $\gamma$.

We can interpret the sufficient condition in terms of the concavity of the generalized Tullock contest function used. Smaller values of the parameter $\gamma$ make the objective function of candidates more concave and an increase in the party's aggregate effort does not increase the winning probability of the party by too much.

\section{Proof of Theorem 2 and the regularity condition}

The equilibrium condition is

$$
p_{j}=\frac{\left(E_{j}\left(p_{j}\right)\right)^{\gamma}}{\left(E_{j}\left(p_{j}\right)\right)^{\gamma}+\left(E_{-j}\left(1-p_{j}\right)\right)^{\gamma}} .
$$

We first derive a condition that guarantees that the equilibrium is unique for given lists

by parties. To show that, we consider the function $G\left(p_{j}\right)=p_{j}-\frac{\left(E_{j}\left(p_{j}\right)\right)^{\gamma}}{\left(E_{j}\left(p_{j}\right)\right)^{\gamma}+\left(E_{-j}\left(1-p_{j}\right)\right)^{\gamma}}$. As $G(0)<0$ and $G(1)>0$, we need to show that $G^{\prime}\left(p_{j}\right)>0$.

Taking the derivative, we get:

$$
G^{\prime}\left(p_{j}\right)=1-\frac{\gamma\left(E_{j}^{\gamma}+E_{-j}^{\gamma}\right) E_{j}^{\gamma-1} \frac{\partial E_{j}}{\partial p_{j}}-\gamma E_{j}^{\gamma}\left(E_{j}^{\gamma-1} \frac{\partial E_{j}}{\partial p_{j}}-E_{-j}^{\gamma-1} \frac{\partial E_{-j}}{\partial p_{-j}}\right)}{\left(E_{j}^{\gamma}+E_{-j}^{\gamma}\right)^{2}} .
$$


Rewriting the above, we obtain

$$
\begin{aligned}
1-\frac{\gamma E_{j}^{\gamma-1} E_{-j}^{\gamma} \frac{\partial E_{j}}{\partial p_{j}}+\gamma E_{-j}^{\gamma-1} E_{j}^{\gamma} \frac{\partial E_{-j}}{\partial p-j}}{\left(E_{j}^{\gamma}+E_{-j}^{\gamma}\right)^{2}} & =1-\frac{\gamma E_{j}^{\gamma} E_{-j}^{\gamma}\left(\frac{\partial E_{j}}{E_{j} \partial p_{j}}+\frac{\partial E_{-j}}{E_{-j} \partial p_{-j}}\right)}{\left(E_{j}^{\gamma}+E_{-j}^{\gamma}\right)^{2}} \\
& =1-\frac{\gamma\left(E_{-j}^{\gamma} \frac{p_{j}}{E_{j}} \frac{\partial E_{j}}{\partial p_{j}}+E_{j}^{\gamma} \frac{p-j}{E_{-j}} \frac{\partial E_{2}}{\partial p_{-j}}\right)}{\left(E_{j}^{\gamma}+E_{-j}^{\gamma}\right)} \\
& =1-\gamma\left(p_{-j} \eta_{j}+p_{j} \eta_{-j}\right) .
\end{aligned}
$$

where $\eta_{j}=\frac{p_{j} \partial E_{j}}{E_{j} \partial p_{j}}$ is team $j$ 's winning probability elasticity of aggregate effort.

Thus, under the following regularity condition, $G^{\prime}\left(p_{j}\right)>0$.

Regularity Condition: $\gamma\left(p_{-j} \eta_{j}+p_{j} \eta_{-j}\right)<1$.

A sufficient condition for this regularity condition to hold is that $\gamma<2 / n$. To prove this we first derive the following lemma.

Lemma : $\eta_{j}<n / 2$.

Proof: As $E_{j}^{*}=\sqrt{\sum_{m=1}^{n} \gamma \frac{a_{m}^{2}}{c_{m j}}\left(M_{j}^{m} V+M_{j}^{m a j} W_{m}\right)}$, we have:

$$
\begin{aligned}
\eta_{j} & =\frac{p_{j} \partial E_{j}}{E_{j} \partial p_{j}} \\
& =\frac{p_{j}}{E_{j}} \frac{\sum_{m=1}^{n} \gamma \frac{a_{m}^{2}}{c_{m j}}\left(\frac{M_{j}^{m}\left(m-(n+1) p_{j}\right)}{p_{j}\left(1-p_{j}\right)} V+\frac{M_{j}^{m a j}\left(k^{M a j}-(n+1) p_{j}\right)}{p_{j}\left(1-p_{j}\right)} W_{m}\right)}{2 \sqrt{\sum_{m=1}^{n} \gamma \frac{a_{m}^{2}}{c_{m j}}\left(M_{j}^{m} V+M_{j}^{m a j} W_{m}\right)}} \\
& =\frac{1}{2 E_{j}\left(1-p_{j}\right)} \frac{\sum_{m=1}^{n} \gamma \frac{a_{m}^{2}}{c_{m j}}\left(M_{j}^{m}\left(m-(n+1) p_{j}\right) V+M_{j}^{m a j}\left(k^{M a j}-(n+1) p_{j}\right) W_{m}\right)}{\sqrt{\sum_{m=1}^{n} \gamma \frac{a_{m}^{2}}{c_{m j}}\left(M_{j}^{m} V+M_{j}^{m a j} W_{m}\right)}} \\
& <\frac{1}{2 E_{j}\left(1-p_{j}\right)} \frac{\sum_{m=1}^{n} \gamma \frac{a_{m}^{2}}{c_{m j}}\left(M_{j}^{m}\left(n-(n+1) p_{j}\right) V+M_{j}^{m a j}\left(n-(n+1) p_{j}\right) W_{m}\right)}{\sqrt{\sum_{m=1}^{n} \gamma \frac{a_{m}^{2}}{c_{m j}}\left(M_{j}^{m} V+M_{j}^{m a j} W_{m}\right)}} \\
< & \frac{n-(n+1) p_{j}}{2\left(1-p_{j}\right)}=\frac{n\left(1-p_{j}\right)-p_{j}}{2\left(1-p_{j}\right)}<n / 2 .
\end{aligned}
$$

Thus, under the regularity condition, we have $\gamma\left(p_{2} \eta_{1}+p_{1} \eta_{2}\right)<\gamma\left(p_{2}+p_{1}\right) n / 2=\gamma n / 2$. Thus $G^{\prime}\left(p_{1}\right)>0$, and the equilibrium of the game is unique for given party lists. 
To finish the proof of theorem 2, we consider a comparative static. The parameter $\Delta$ corresponds to the increase or decrease in the cost parameter of a candidate. We want to see what happens when we change the cost parameter of one candidate. The direct effect is to change $E_{1}$, but that also changes $p_{1}$, which leads to further changes in $E_{1}$ and $E_{2}$. We want to consider the general equilibrium effect.

Equilibrium is defined by:

$$
p_{1}-E_{1}\left(p_{1}, \Delta\right) /\left(E_{1}\left(p_{1}, \Delta\right)+E_{2}\left(p_{1}, \Delta\right)\right)=G\left(p_{1}, \Delta\right)
$$

Using the implicit function theorem, we get:

$$
\begin{aligned}
\frac{\partial p_{1}}{\partial \Delta} & =-\frac{\partial G / \partial \Delta}{\partial G / \partial p_{1}}=-\frac{E_{2} /\left(E_{1}+E_{2}\right)^{2} \cdot \frac{\partial E_{1}}{\partial \Delta}}{\partial G / \partial p_{1}} \\
& =\frac{E_{2}}{\left(E_{1}+E_{2}\right)^{2} \cdot \partial G / \partial p_{1}} \frac{\partial E_{1}}{\partial \Delta}
\end{aligned}
$$

Under the regularity condition, $\partial G / \partial p_{1}>0$. So a change in the cost parameter that leads on an increase in the aggregate effort also leads to an increase in the probability of winning. This means that changes in the list order that lead to an increase in aggregate effort will also lead to an increase in the electoral success of the party.

\section{Proof of Proposition 3}

As stated as theorem 2, the party will assign ranks according to $M_{j}^{m}=m C_{m}^{n} p_{j}^{m}\left(1-p_{j}\right)^{n-m+1}$.

As $m C_{m}^{n}=n C_{m-1}^{n-1}$, we need to look at the distribution of $M_{j}^{m}=n p_{j}\left(1-p_{j}\right)\left(C_{m-1}^{n-1} p_{j}^{m-1}\left(1-p_{j}\right)^{n-m}\right)$. Using a standard argument about the mode of the binomial distribution shows that $M_{j}^{m}$ is largest when $k=\lfloor n p+1\rfloor$. 